\title{
A Diachronic-Synchronic Review of Gender in English 1
}

\author{
Jesús Fernández-Domínguez \\ University of Jaen \\ jesusferdom@gmail.com
}

\begin{abstract}
Why does man occur more frequently in the English language than woman does?2 Has the expression of gender evolved through the centuries or is it a non-changing linguistic universal? To what extent are inflections and word-formation processes able to convey gender in present-day English? This paper reviews a number of questions which have raised interest among scholars for many years, and which can now be reconsidered from a 21 st-century perspective. To this end, the expression of gender is examined and illustrated from Old English to contemporary English to observe the alternatives which language provides and the differences in each of the periods covered. This allows taking a broad view of the state of the art, which seems necessary for an understanding of how biological sex can be expressed in the English language.
\end{abstract}

\section{Introduction}

Gender has been a widely studied topic along the history of linguistics due to the close relationship is bears to reality. On the one hand, some studies have focused on the linguistic reflection of the historical repression over women, arguing for a gender-neutral language. On the other hand, closely connected with this, other works have dealt strictly with the linguistic side of gender, i.e. how biological sex is expressed in the language (e.g. Corbett, 1991; Hidalgo, 2000). This subject and its treatment seem to us particularly appropriate here for a number of reasons.

Firstly, because gender is in many ways unpredictable; it is not universally present in language, for some languages have never had gender (for example, Chinese), and others have lost it (for example, Persian; cf. Ibrahim, 1973: 12, 17, 25, 27). In fact, even though gender is common in Indo-European languages, it is often differently motivated and, 
therefore, differently assigned. Why this is so remains an open question today, although the dominant view is that probably not as a result of different cultural backgrounds, which have sometimes been held responsible for the different gender interpretation of universal notions such as, for example, death (masculine in German -der Tod-, feminine in Spanish -la muerte-, and neuter in English -the death) (cf. Platzer, 2001: 35, 42).

Secondly, because although gender has a direct influence on the morphology and the syntax of languages, very little has been discerned about this topic since the classical grammars (see Joseph, 2005: 474-475; Mitchell \& Robinson, 2007²: 11-13). A third reason is that gender is one of the categories of English that has most radically changed in time, to the extent that the original gender system of this language can hardly be recognized nowadays. Its historical development seems particularly attractive, since it does not simply consist in loss of detail, as is the case of the category number, or in morphological regularization by decline of inflections, as in the category case.

If the last years have meant a growth in gender studies, it can now be stated that many of the prejudices about studies of this kind are being overcome. It seems now a good moment to look back and explain how English has gone through different stages for gender expression along the centuries. It all makes this a multi-faceted subject, and one that readily lends itself to a two-level study of language: diachronic and synchronic.

The sequence of contents adopted for this paper is in line with the chronological criteria usually employed for the English language, and is thus divided into two main parts. After the preliminary remarks set in section 2 , section 3 is a diachronic description of gender in the three main periods of the history of English. Subsequently, section 4 is a synchronic description of gender in contemporary Standard English, and it basically consists in a review of the three-fold system of masculine, feminine and neuter gender. Finally, some conclusions are gathered in section 5 .

The examples in this paper have been taken from the British National Corpus (hereafter $\mathrm{BNC}$ ), and illustrations from bibliographical references have been used occasionally.

\section{Preliminary remarks}

Gender is one of the classical grammatical categories ${ }^{3}$ operating in contemporary Standard English. The three-fold distinction (male, female and non-sexed) will be found most predominantly in animate entities and, as these are denoted by the word-class noun, it is logical that this word-class should characteristically display gender contrast. This, however, often extends from the category noun to those categories which are closely related to it, either by replacing it (typically pronouns), or by providing some qualification (typically pronouns and adjectives). Gender is not present in those word-classes that do not make a direct reference to entities or concepts like the ones denoted by nouns, for instance verbs, adverbs, prepositions, or conjunctions ${ }^{4}$.

This all is true of languages like Spanish, French or German, but not entirely so of English. The fact is that from these preliminary considerations gender may be defined as 
"[...] a grammatical classification of nouns, pronouns, or other words in the noun phrase, according to certain meaning-related distinctions, especially a distinction related to the sex of the referent" (Quirk et al., 1985: 314).

In other words, gender is a morphosyntactic category, a convention that tends to encode biological sex linguistically. But, however true this definition may be for most languages, the fact is that gender assignment does not always rely on sex distinction. Corbett (1991: 7-8; cf. also Freeborn, 1998²; Hellinger, 2001; Lass, 2006: 106-107) shows two basic types of information about nouns that may determine gender assignment:

i) their meaning (i.e. gender is assigned on semantic grounds), and

ii) their form, which in turn may involve either the word-structure (which comprises derivation and inflection), or the sound-structure (i.e. their phonology).

In these two cases, the criterion is strictly formal. These two systems are not mutually exclusive, and languages may use different combinations of them. Our first step will be a diachronic review of the gender system of the English language, for it is one of the aspects most severely affected by its historical change.

\section{A diachronic description of gender in English}

The convention followed in this paper considers three major periods in the history of English: Old English (hereafter OE), Middle English (hereafter ME), and Modern English (hereafter ModE). Following Fernández (1982: 23), it is here understood that OE extends from the 5th to the 12th century, ME from the 12th to approximately the 16th century, and ModE from the 16th century onwards. Of course, this division is to some extent arbitrary, since no strict segmentation of a continuously changing entity like language is entirely exact.

Over these three periods, English went through a number of major changes that altered its structure to the extent that it can be considered a Germanic language on account of its history, but not of its current nature (cf. Barber, 1993: 80; Blake, 1996: 31; Freeborn, $1998^{2}$ ). Certainly, English is today a language substantially different from what it was in the OE period, and this is a result of two major opposite tendencies: synthesis and analysis. The former favours an inflectionally-based grammar, that is, the expression of syntactic functions and grammatical meaning by changes in the words, most usually by case inflections. The opposite process, analysis, begins to operate in the OE period or even before that, for $\mathrm{OE}$ inflections were to a large extent simplifications of the Proto-Germanic patterns (Hogg, 1992: 122-123; Barber, 1993: 116). However, the influence of this analytic tendency did not effect great changes in the language until around the 13th century according to the chronology by Fernández (1982: 209; cf. also Hogg, 1992; Lass, 2006).

This analytical process reversed the synthetic tendency of OE, as it progressively introduced the use of such grammatical auxiliary elements as prepositions, verbal 
auxiliaries, and a fixed word-order. These new resources can be viewed diachronically as a compensation for the progressive reduction of the inflection of the major word-classes, which increasingly became lexical elements nearly without any marks signalling their grammatical categories and syntactic relations ${ }^{5}$.

As will be seen in the following sections, it was the second movement of the two mentioned at the beginning of this section, analysis, that had a direct influence on the expression of gender in English.

\subsection{Old English, or grammatical gender}

As in contemporary English, gender in OE expressed the contrast between three types of gender: masculine, feminine, and neuter. This distinction had been inherited from the IndoEuropean nominal system, which remained practically unaltered in Germanic (Bammesberger, 1992: 47-48), and which is still in full use in many Indo-European languages. Gender contrast was most frequently expressed by use of inflectional paradigms specific for one or more of the three genders in the word-classes noun, pronoun, and adjective.

Gender was allotted to nouns partly on natural and partly on grammatical grounds. On natural grounds because, as a rule, male adult persons and animals were given masculine gender, female adult persons and animals feminine gender, and young persons and animals neuter gender, that is, gender paralleled the natural sex distinctions of some real-world entities. But gender was most often assigned on strictly grammatical grounds, in particular, in accordance with the form of words rather than with sex affinity. For this reason, its effect was not that of matching and representing biological sex, but rather "[...] a classifying device that predicts concord", regardless of the properties of the real-world entities denoted by the words (Lass, 1992: 106).

Thus, for example, nouns ending in '-a', '-op', or 'dōm' were ascribed masculine gender, which explains the masculine reference of se mōna (ModE "the moon"), of se fis cop (ModE fishing), or of se cynedom (ModE kingdom). By contrast, the endings '-u', 'ung', '-nes(s)', or '-ett' were given feminine gender, as in sēo giefu (ModE the gift), sēo ánnes (ModE the oneness), sēo axfnung (ModE the evening), sēo ylfett (ModE the swan), or sēo byrpenn (ModE the burden). And, finally, the nouns ending in '-lac' and '-en' were given neuter gender, as in pat witelac (ModE the punishment) or pat mag $\mathrm{g} d e n / m a d e n$ (ModE the maid) (Fernández, 1982: 210-211).

Co-existence of these two gender assignment systems, the natural and the grammatical one, is explained because there are no exclusively morphological systems, i.e. morphological criteria are used when the semantic criteria fail or are not evident (Corbett, 1991: 34). In fact, it has for a long time been thought that grammatical gender must have been an extension of natural gender (Ibrahim, 1973: 30). Whether this is true or not, the fact is that entities or concepts other than persons and animals (whether young or adult) clearly outnumbered the animate ones, which were consequently liable to gender classification on natural grounds. For this reason, gender in nouns was, more often than 
not, grammatically- rather than naturally-motivated.

Therefore, the gender declensions of nouns were greatly determined by such arbitrary considerations as the base form of the nouns. Nouns were inflected on the basis of two major paradigms, 'vowel declension' and 'consonant declension' (also called 'strong' and 'weak' respectively), which in turn had various declensional patterns for various stems (cf. Fernández, 1982: 211-221; Hogg, 1992: 124-138; Baugh \& Cable, 1993²: 55-56; Blake, 1996: 64-65). Thus, there were the following sets of case-inflections for the strong declension of nouns:

i) '-a' theme or stem. These nouns were given masculine or neuter gender.

ii) ' $-\overline{0}$ ' stem. These other nouns were given feminine gender.

iii) '-i' stem. These nouns could be given any of the three genders, masculine, feminine or neuter.

iv) '-u' stem. These nouns could be masculine or feminine.

The weak declension had three different inflectional models:

i) ' $-\mathrm{a}$ ' stem. Nouns of masculine gender.

ii) '-e' stem. Nouns of feminine gender.

iii) A second, rather unproductive pattern for the '-e' stem. Nouns of neuter gender.

As stated above, gender was morphologically marked not only in nouns, but also in those word-classes which usually bear a close relation with nouns and which can accordingly be called 'adnominal', i.e. adjectives and pronouns. OE adjectives took inflection for all the grammatical categories for which nouns did, namely number, gender, case, and class ('short stem' and 'long stem'), as well as for two different syntactic positions ('strong' and 'weak') (Valera 1996: 53; Mitchell \& Robinson, 2007': 30-32). The difference between the three genders remained fully active even when adjectives inflected for the comparative and superlative degrees of inferiority or of superiority, because they still retained their normal inflection: weak inflection for comparatives of superiority (after the comparative suffix '-ra'), and weak and strong inflection for superlatives of superiority (after the superlative suffixes '-est', or its variants '-ast', '-ost', or '-ust').

Finally, several classes of pronouns showed different forms for each of the three genders. The pronouns most frequently used, that is, personal (only for the forms of the third person ${ }^{6}$ ), demonstrative, interrogative and indefinite, were systematic in expressing gender contrast by use of different patterns in their singular forms, their plurals being common to all three genders. Other pronominal forms, such as the relative pronouns, did not change for gender in OE (let alone in ME or ModE), and sometimes did not even accept inflection for case.

However, the contrast between the forms of these paradigms was not always as sharp as could be expected. Despite the tremendous specialization of the complex inflectional system of $\mathrm{OE}$, gender was not one of the grammatical categories most clearly represented 
by this inflectional system. This is only logical if, as remarked by Lass (1992: 103), “[...] while the categories of gender, number and case were real enough, it was virtually impossible for any single noun form to be uniquely marked for all three (not so for determiners and pronouns [...])".

Certainly, except for the inflections of pronouns and of those nouns which were specifically allotted one gender (for example, feminine gender for nouns in '- $\overline{0}$ '), the similarities between the patterns of different genders of one same paradigm are more than occasional, especially between the patterns of masculine and neuter. Differences in the declensions tended to occur in the nominative and accusative, while the genitive and dative (and instrumental, when existing) often remained identical for all three genders or, at least, for the masculine and neuter.

In fact, leaving aside the class pronoun, the declensions of nouns and adjectives did not always vary significantly in practice in terms of gender. This shows that, since the occurrence of a given mark of number, gender, or case in the noun necessarily required the same mark in its co-occurring pronouns or adjectives, the expression of gender was supported by the paradigms of these three word-classes together rather than by each of them in isolation.

\subsection{Middle English, a time of change}

The end of the OE period and the beginning of ME coincide with a turning point in the transition of English from a synthetic to an analytical language, namely the substitution of an analytical grammar for the collapsing inflectional system of OE. This proved crucial for the change of the expression of gender in English: since gender distinctions were expressed by use of different inflectional morphemes in nouns, adjectives and pronouns, the gradual loss of inflections triggered loss of the gender marks too, and their replacement by some non-inflectional gender system.

The levelling and loss of inflections, often described as neutralization in '-e', was the result of a number of phonological and analogical changes in close interrelation one with another and which probably took place in this order. These changes basically consisted in a transformation of final '- $m$ ' into '- $n$ ' in unstressed syllables, and subsequent loss of this '-n' as well as a weakening of the surviving unstressed vowels '-a-', '-e-', '-o-' and '-u-' to a sound usually represented in print as '-e-', which would eventually disappear too (cf. Moore, 1968: 72, 79 et passim; Burrow \& Turville-Petre, 1992: 20; Baugh \& Cable, 1993 $\left.{ }^{4}: 154-155\right)$.

This development was only to be expected if we consider that, as a Germanic language, OE tended to stress the first syllable of words (unless that syllable were a prefix). This left the final syllables, which carry the inflections, in an unstressed position that gradually became reduced to one weak syllable whose vowel was equivalent to the unstressed 'schwa', orthographically represented with the letter '-e' and, eventually, disappeared (cf. Blake, 1996: 25). This process ran parallel to the changes in the inflections: it extended gradually from the north and east dialects in approximately the 10th century, to the south 
and west ones which maintained significant rests of inflections (and, consequently, of natural gender) until the 14th century (cf. Fernández, 1982: 304; Burrow \& Turville-Petre, 1992: 21; Lass, 1992: 107-108; Guzmán, 2001).

Neutralization of inflections began in nouns with the reduction of the various declensions mentioned earlier on under section 2 to the following three major ones:

i) That of '-a' stems was kept for the nouns of the OE paradigm in '-a', for the masculine and neuter nouns of the paradigms in '- $\mathrm{i}$ ', in '- $\mathrm{u}$ ', and for some of the nouns that inflected following some of the minor declensions.

ii) That of '- $\overline{\mathrm{o}}$ ' stems was kept for the nouns of the OE paradigm in ' $\overline{\mathrm{o}}$ ', and for the feminine nouns of the paradigms in ' $-\mathrm{i}$ ' and '-u'.

iii) That of '-n' stems for all other nouns, masculine, feminine and neuter.

However, these three basic declensions of nouns gradually coalesced to form one single paradigm by extension of the nominative ending '-e' to all cases of the singular number (with later addition of final '-s' to the genitive), and '-(e)s' to all cases of the plural. In the case of the word-class noun, this levelling was also favoured by the considerable similarity of many of the inflectional suffixes of the various declensions, which supplied an additional basis for analogical extension of some endings to the all cases (Lass, 1992: 104).

In adjectives, the reduction of inflections was very similar to that of nouns, and had been at work since the late OE period and the beginning of ME (cf. Mossé, 1952: 91). In time, the forms of the nominative were adopted for the rest of cases after gradual neutralization of final '-m' to '-n', of the vowels to '-e', and their eventual loss in the oblique cases of the strong and weak paradigms. As a result, in the late ME adjectives could only adopt two forms, with and without final '-e'. These declensions, which had remained in use at the beginning of this period, thus became definitely neutralized in their forms (Moore, 1968: 51-52).

The neutralization of the inflectional patterns of adjectives also affected the comparative and superlative degrees of superiority. The OE inflections for the comparative and the superlative first became '-re' and '-est' in ME, although by the end of this period they had evolved to '-er' and '-est'. Several lexical units retained the OE suppletive forms for the expression of degree and, again, an analytical structure with the adverbs 'more' and 'most(e)' appeared or became more common for the expression of degree since the 14th century. The extreme simplification of the morphology of the adjective made it necessary to compensate for the loss of inflections and maintain the reference of the adjective and its syntactic relations unambiguous (cf. Valera, 1996: 51-56). The currently well-known prenuclear distribution of most $\mathrm{OE}$ noun-modifying adjectives, immediately after any cooccurring pronouns, thus became regularized and adopted as a norm in ME (cf. Fernández, 1982: 342; Burrow \& Turville-Petre, 1992: 44; Joseph, 2005).

Finally, the neutralization of inflections in the pronoun was not so extensive, and this is manifest from the closer parallelism between some pronouns of $\mathrm{OE}$ and those of contemporary English. In the case of personal pronouns the main changes consisted in a 
dialectal diversification of alternative forms of the OE pronouns. These, however, were just different orthographical representations of the same pronouns. This was to be expected because gender in personal pronouns of the third person was not grammatically-, but naturally-motivated, in agreement with the already developing natural gender system of English (cf. Mitchell \& Robinson, 20077 106-107). Apart from these orthographical alterations, the three-fold gender distinction of personal pronouns of the third person in singular did not change substantially.

The demonstrative and interrogative pronouns became affected by the neutralization of inflections at a later time (from the 13th century onwards), but also more dramatically. In fact, of the three grammatical categories for which these pronouns could take inflection (case, gender and number) at the end of the period of $\mathrm{OE}$ and beginning of ME, only one (that of number) remained active at the end of ME (Fernández, 1982: 309-311). The interrogative pronouns, by contrast, did not retain any systematic inflection and their different forms soon became reduced to one for all cases, genders and numbers.

Therefore, the expression of gender in ME became badly affected by the loss of inflections of nouns, but especially of adjectives and pronouns, because agreement of these elements with their superordinate nouns provided a richer and more distinctive gender mark than the inflection of nouns itself (see Jespersen, 1909-49, vol. VII: 175; Lass, 1992: 106; for a similar situation in Germanic, see Bammesberger, 1992: 52).

As pointed out by Mossé (1952: 45-46; cf. similarly, Lass, 2006: 71), whereas gender was very easy to distinguish by way of the inflections in OE, the use of practically the same inflectional patterns for all three genders in ME eliminated from words their distinctive marks of gender. In early ME, grammatical gender survived to a limited extent supported by gender distinctions in demonstrative and personal pronouns, but the eventual neutralization of declensions in the former, as well as in adjectives and nouns, led to complete loss of the major resource for the expression of gender in English. This made the classification of nouns into one or the other gender not only difficult to maintain, but redundant or even pointless. As a consequence, new criteria for gender assignment had to be adopted, and this was most simply done by allotting gender to animate entities according to their sex (i.e. masculine and feminine, as in OE), and giving neuter gender to the nouns that could not be naturally ascribed to any of the two previous gender classes, masculine and feminine (cf. Fernández, 1982: 304; Burrow \& Turville-Petre, 1992: 22, 38; Lass, 1992: 106; Guzmán, 2001). Why grammatical gender was replaced by natural one can be explained because natural gender was already present in $\mathrm{OE}$, and for this reason easily extended to other entities that had lost their gender assignment marks.

Of course, the transition from one system to the other was gradual, and one in which the pronominal system played a major role: with the relaxation of grammatical gender and the loss of inflections, pronouns increasingly adopted gender concord on natural grounds, which sometimes involved a clear conflict with grammatical gender even in the OE period (cf. Jespersen, 1909-49, vol. VII: 178; Lass, 1992: 107; Traugott, 1992: 177-178; Baugh $\&$ Cable, $\left.1993^{4}: 162\right)$. This all explains why entities which originally were of masculine gender in OE (e.g. ModE moon), later became neuter as a result of the loss of their 
distinctive endings and of their lack of evident male properties.

\subsection{Modern English, or natural gender}

By the beginning of ModE, the major developments affecting inflection and the morphosyntax of nouns, adjectives, pronouns, and articles had already taken place, and in this respect ModE bears witness only to some phonological adjustments and minor changes (Görlach, 1991: 79 et passim; Baugh \& Cable, 1993: 235). In fact, the developments of ModE are rather of a syntactic nature, as new patterns were adopted to make up for inadequacies in the grammatical system resulting from the linguistic upheaval of ME (Görlach, 1991: 95). Within this system, nouns nowadays retain as their systematic inflection only the endings '-s' or '-es' for plural number and '-'s' or only the apostrophe, '-', for the genitive case, which overall makes up a poor inflectional paradigm, especially if compared with the variety of declensions of OE (cf. Görlach, 1991: 107; Barber, 1993: 159; Baugh \& Cable, $1993^{4}: 235-236$ ). With the neutralization of the last inflectional differences, the adjective also adopted its current morphological configuration, i.e. as a word lacking inflection for all grammatical categories except for degree.

Finally, pronouns proved considerably more resistant to levelling of inflections, to the extent that they can be considered the only significant rest of the synthetic grammar of OE (Fernández, 1982: 382-386; Baugh \& Cable, 19934: 236-239). This is especially so in the case of personal pronouns. Personal pronouns of the third person (the only ones that express gender distinction) hardly changed, except for orthographical regularization, and for the development of a form (its) for the genitive singular of the neuter gender in order to avoid confusion with the form (his) which in ME was identical with its masculine counterpart. Similarly, interrogative pronouns were not substantially different from the ones in ME, with some reduced inflection for case in the pronoun who (whose in the genitive, and whom in the accusative and dative), but not in what or which. Demonstrative pronouns did not prove so resistant, and retained part of their original inflection, the one of number, but not those of gender or case.

The general picture resulting from these processes is, in a word, that grammatical gender became nearly totally absent from ModE, and was replaced by natural one. The following sections are a review of gender in contemporary English.

\section{A synchronic description of gender in English}

\subsection{The distinction "masculine" / "feminine" / "neuter"}

It has been mentioned that, although gender is usually associated with animate entities, it is not a linguistic universal. The two alternative gender systems, natural and grammatical, have evolved through the centuries with the result that, in contemporary English, gender is generally assigned on strictly natural, semantic grounds (i.e. depending on the biological 
sex of entities). This system of natural gender is most evident in the case of animate entities, for these are characterized by their 'biological' or 'intrinsic sex' (Mathiot, 1979: 1). In this respect, the three-fold morphosyntactic distinction of masculine, feminine and neuter gender is valid not just for English or for some languages of the Indo-European family of languages, but as a cross-linguistic generalization too (Frawley, 1992: 100).

The general rule goes that the choice between the three terms of gender in English is primarily determined by the sex properties of the referent. But gender assignment can also be determined, to a limited extent, by "[...] the speaker's attitude to the referent" (Huddleston, 1984: 289-290). This entails that, contrary to the rule of natural gender, linguistic gender and biological sex do not always match regularly (Frawley, 1992: 99). Masculine and feminine reference can thus be selected for sexless entities on an arbitrary basis as a result of what has been defined as "a certain emotional attitude" (Welte, 1989: 85), or "a strong feeling of affection" (Jespersen, 1909-49, vol. VII: 213-214; Baugh \& Cable, $1993^{4}: 11$ ), just as neuter reference can be selected for animate entities which have a perfectly clear sex specification. This kind of gender assignment, which has sometimes been called 'metaphorical gender' (Welte, 1989: 85), leads to several special cases of gender assignment.

\subsubsection{Masculine reference}

In the first place, masculine reference is used for generic reference, as an unmarked element of this three-term system, i.e. use of a particular term without regard to the sex of its referent(s) (Gramley \& Pätzold, 1992: 263):

(1) Everyone has his own story of being ignored when requesting information [...]

This generic reference also explains the use of masculine pronouns for

i) reference to animate entities (whether mammals, birds, reptiles, insects, etc.) (Jespersen, 1909-49, vol. VII: 209):

(2) A mouse found a beautiful piece of plum cake, the richest and sweetest that bakers could make [...]. "My stars!", cried the mouse while his eyes beamed with glee,

ii) the lexically-marked masculine noun "man" for generic reference to human beings instead of the form marked for the feminine ("female"):

(3) The State acknowledges that man, in virtue of his rational being, has the natural right [...] to the private ownership of external goods,

iii) or the use of masculine (or feminine) gender for jobs on the grounds of the habitual sex ascription to the job, for instance, female for nurses (cf. Quirk et al., 1985: 315-316):

(4) This nurse, I was surprised to discover, was a man

A consequence of this use of masculine forms for generic reference is that when a two sexword is used without further specification, it will most often be understood as referring to a man, as in (5): 
(5) “The other day an Italian told me..”. (Jespersen, 1909-49, vol. VII: 197)

Masculine reference extends from generic contexts where a masculine form is used, to generic contexts, even if no gender mark is used. However, use of this type of forms and of gender assignment priming masculine rather than feminine reference has been of late claimed to be sexist. Several alternatives have been proposed to avoid sexism, many of which are linguistically congruent, but not really operative, such as the use of written forms like 's/he' or 'wo/man' (Quirk et al., 1985: 315), as in (6) and (7). Other more successful expressions are preferred today, for example, the generic use of the pronoun one, as in (8):

(6) The tutor can have the responsibility of arranging the date, time and venue of the examination, and acting as invigilator if $s / h e$ wishes

(7) Use your notes to compile a summary of the candidate and why you selected him/her for the job

(8) One can never be defeated if one stands on a matter of morality

In this context, the third person plural pronoun, yields less wordy and clumsy constructions and has existed in this use in English for about four centuries:

(9) Everyone who wants to act professionally should try to see as much drama as they possibly can $[\ldots]$

Finally, general words lexically neutral to gender (flight attendant, firefighter, letter carrier or chairperson instead of steward or stewardess, fireman, mailman or chairman, respectively) are also used as a lexical resource to avoid sexist language:

(10) A part-time firefighter is needed for Middleton-in-Teesdale station

\subsubsection{Feminine reference}

Feminine reference is frequently selected for vehicles such as ships, trains, motor-cars, or for engines in general. This, according to Jespersen (1909-49, vol. VII: 213-214; cf. also Quirk et al., 1985: 318; Welte, 1989: 91-92), is especially the case of those speakers who are more familiar with these instruments or want to make explicit a special attitude of affection or familiarity to the object:

(11) She's an absolute bastard, this truck. (Quirk et al., 1985: 318)

(12) The tank is the queen of the battlefield. (Jespersen, 1909-49, vol. VII: 213-214)

Countries and cities, when presented as geographical units are assigned neuter reference following the principles of natural gender but, when seen as cultural units, they are also referred to as female entities. Compare the following examples by Welte (1989: 91-92) and by Quirk et al. (1985: 318) respectively; (13) shows a country or city viewed as a neuter 
entity, whereas (14) presents the same entity as female:

(13) Cuba is an island. You can sail around it in two days

(14) France has been able to increase her exports by 10 per cent over the last six months

\subsubsection{Neuter reference}

And thirdly, neuter gender is not limited to non-sexed entities, even though these are the nouns for which neuter gender is most frequently used in English. In fact, neuter gender is used for sexless entities on the one hand, but also for sex-unspecified entities on the other (Welte, 1989: 85):

(15) Tobacco, pills and medicines, and alcohol can all harm your baby before it is born

Lack of sex-specification can be due to two major reasons. One is 'underdevelopment' or 'lack of salience of sex' (Zubin \& Köpcke, 1986: 144-145), and occurs in animate entities which show sex contrast, but for which such a contrast is viewed as irrelevant, or is unknown. This is the case of "[...] children, adolescents or individuals form whom sex is otherwise irrelevant or nonsalient" (Frawley, 1992: 102-103). To this group belong also non-human, animate entities, as is the case of animals, especially if their sex is not obvious, as in plants and lower animals:

(16) Different sized crabs utilise different sized shells, and as a crab grows it must change shells regularly to accommodate its larger body

However, if there is a special interest in a particular animal, masculine or feminine reference is selected instead (Jespersen, 1909-49, vol. VII: 205-209). Thus, when in connection with their brood, birds are preferably referred to as feminine (Jespersen, 190949, vol. VII: 209-210) but, on the whole, double reference can be used in the same sentence:

(17) The robin builds its nest in a well-chosen position [...] and, after the eggs have hatched, the mother bird feeds her young there for several weeks. (Quirk et al., 1985: 342)

The neuter form is also used for any antecedent for which the masculine or feminine forms are not appropriate, usually for abstract entities or facts, as in (18):

(18) The headline was thick black letters. "Killer Dog" it said and there was a picture of a dead lamb with the farmer beside it. "It's a shame. People shouldn't let their dogs roam”, said Philip's Mum. "It's irresponsible, that's what I call it". 
The resulting system of gender reference can be summarized following Welte's (1989: 86) seven different genders depending on the type of reference nouns may admit. Rather than interpreting the following as a classification of seven different types of gender, as originally proposed, this is a brief list of the possible gender assignments that nouns may admit based on their referents. Thus, whereas some nouns can only have one type of reference (i, ii or iii), others are double-gender (iv, v, vi), or multiple-gender nouns (vii):

i) Masculine only: for male human beings (father, boy, king).

ii) Feminine only: for female human beings (mother, girl, queen).

iii) Neuter only: inanimate (non-sexed) objects (book, tree, room).

iv) Masculine or feminine: male or female human beings. These have been described as 'common gender' (Welte, 1989: 87), or 'dual gender' (Quirk et al., 1985: 315), and usually are nouns in '-er' (driver, employer, singer), '-ian' (servant, inhabitant, vegetarian), or '-ist' (loyalist, artist, typist) ${ }^{7}$.

v) Masculine or neuter: male animals (billy-goat, ram, bull, drake, boar, cock), and personifications of certain objects of the human physical or mental universe (sun, river, summer, winter, love, death, time, war).

vi) Feminine or neuter: female animals (nannygoat, ewe, sow), personifications of certain objects of the human physical or mental universe (moon, earth, night, day, spring, world), countries and cities (England, China, India), certain abstract concepts (faith, virtue, fortune, peace, liberty, mercy, wisdom), certain mechanical objects with which the speaker has a strong emotional attachment (ship, engine, locomotive, plane, car).

vii) Masculine, feminine or neuter: animate beings whose sex is indeterminate (baby, infant, child, cat, dog). This is often the case of young children or lower animals (fish, birds, reptiles, insects, etc).

\subsection{The realizations of the distinction "masculine" / "feminine" / "neuter"}

Gender in English is sometimes an overt category, i.e. "[...] at least one term of the category is identified by a formal marker of some sort", and sometimes a covert one, i.e. "[...] no term in the category can be identified with a formal marker" (Brown \& Miller, $\left.1991^{2}: 242-243\right)$. Whether it is of one or the other type depends primarily on the wordclass, for it is (at least historically) overt in the word-class pronoun (of the subtype personal), and covert in most nouns (some nouns have overt marks of gender, for instance, feminine nouns in '-ess'), and in the remaining subclasses of pronouns and in adjectives. Contemporary English, therefore, predominantly has covert gender, with almost no formal clues because it does not have inflectionally-marked gender distinctions. The following two sections are about the mechanisms for the expression of gender in English, in which, as noted by Brugmann (1897), "[...] there exist two methods for expressing distinctions in natural gender: either by different roots [...], or by the same root material but with different inflections" (italics as in the original). 


\subsubsection{Inflectional gender marking}

The word-class pronoun is the only one that has a clear inflectional behaviour in contemporary English and, therefore, the one that has changed the least since the $\mathrm{OE}$ period. In fact, permanence of almost the whole original inflectional paradigm of personal pronouns affects not only the category gender, but also the categories number and case, from which a different subclass of pronouns (possessive) arises. This highly inflectional behaviour can readily be observed in the forms for the three cases (nominative, accusative, and genitive), and three genders of the third person personal, possessive and reflexive pronouns, as outlined below (cf. for example, Quirk et al., 1985: 341-343):

\begin{tabular}{|c|c|c|c|c|c|c|c|c|c|c|}
\hline & \multicolumn{6}{|c|}{ Personal } & \multicolumn{2}{|c|}{ Reflexive } & \multicolumn{2}{|c|}{ Possessive } \\
\hline & \multicolumn{3}{|c|}{ Singular } & \multicolumn{3}{|c|}{ Plural } & Singular & Plural & Singular & Plural \\
\hline & Nom & Acc. & Gen. & Nom. & Acc. & Gen. & & & & \\
\hline Masculine & he & him & his & they & them & their & himself & themselves & his & theirs \\
\hline Feminine & she & her & her & they & them & their & herself & themselves & hers & theirs \\
\hline Neuter & it & it & its & they & them & their & itself & themselves & its & theirs \\
\hline
\end{tabular}

Table 1. Pronouns in contemporary English

The clear asymmetry noticeable in Table 1 in that singular number has three different forms for the three genders, whereas plural number has only one form for the three genders can be explained because, in the former case, the pronoun refers to one entity that therefore can be classified as one single gender class. By contrast, in the latter case, i.e. plural number, the multiple entities alluded to by pronouns may belong to various gender classes and, consequently, have to be represented by a general form covering all three genders. All other subclasses of pronouns (reciprocal, relative, interrogative, demonstrative, indefinite, etc.) are neutral to the distinction of gender and cannot express masculine, feminine or neuter reference by inflectional morphology or by word-formation processes.

As for concord, since all nominal sequences can be alluded to by third person personal pronouns, gender distinctions remain expressed, and agreement between nominal sequences and their co-referent pronouns has to be maintained both in gender and number:

(19) A father himself now, he thought of the parents of hers [...] who had lost her and apparently had never searched [...] (Quirk et al., 1985: 347, 356, 768-771)

Thus, selection of one or the other gender in the pronoun is determined by the gender of the co-referent noun in the case, for example, of lexical pairs, and in the rest of cases, by the sex of the entity referred to, that is, is naturally-determined and inflectionally-expressed.

\subsubsection{Word-formation processes for gender marking}

By now, we know that most nouns in contemporary English do not inflect for the 
expression of the grammatical category gender and that, consequently, they lack any gender marks. However, gender can still be expressed or made linguistically explicit in the word-class noun by use of resources other than inflection, namely by morphological and strictly lexical resources (cf. Jespersen, 1909-49, vol. VII: 180-218; Fernández, 1982: 381; Quirk et al., 1985: 315-318; Welte, 1989: 87-92; Pyles \& Algeo, 19934: 254-255; Hidalgo, 2000). The former most often involves use of one of the following two wordformation mechanisms: suffixation or compounding.

Suffixation is most often used to derive morphologically marked feminine forms on the basis of nouns (which, therefore, remain morphologically unmarked as far as gender is concerned). The most widely used suffix is '-ess', as in baroness (baron), goddess (god), hostess (host), princess (prince), or shepherdess (shepherd). By contrast, other OE suffixes which derived feminine nouns from masculine ones, for example, '-en' in fyxen (vixen), gyden (goddess), or mynecen (nun), seem to be no longer productive ${ }^{8}$ (Kastovsky, 1992: 385-386).

Suffixation of '-ess' sometimes involves alteration (in particular, reduction) of the base noun, as in actor (actress), emperor (empress), murderer (murderess), tiger (tigress), or waiter (waitress). Its use may also give rise to irregular forms, as abbott (abbess), duke (duchess), or master (mistress). Other suffixes, most of which are of a foreign origin, can be used to derive feminine forms, but their use is limited to certain lexemes are '-e' (fiancé - fiancée), '-ette' (confidant - confidante), '-ina' (czar - czarina), '-ine' (hero - heroine, Paul - Pauline) or '-trix' (prosecutor-prosecutrix).

Compounding, by contrast, involves use of two lexical stems, of which one is the lexical base, and the other the element that marks gender (in compounds, either masculine or feminine, but not neuter gender). This lexical base invariably is a noun that is not gender-specific and, therefore, requires an additional element marking its gender whenever it is relevant or is to be specified, for instance, friend, guest, student, thief, or writer.

As to the other element of the compound, the stem marking the gender of the base, two different patterns can be considered here depending on its position in relation to the base stem of the compound. In the case of pre-position, the gender of the base noun can be qualified by use of several gender markers:

i) Common nouns (man vs. woman, man vs. maid, and boy vs. girl, for human animate beings. Dog vs. bitch, or cock vs. hen for non-human animate beings), as in man driver vs. woman driver, boyfriend vs. girlfriend, dog-fox vs. bitch-fox, or cock-sparrow vs. hen-sparrow.

ii) Originally proper names specific for masculine or feminine gender, and their respective counterparts (for example, billy or jack for masculine gender, and nanny or jenny for feminine gender). For example, billy-goat vs. nanny-goat or jackass vs. jennyass.

iii) Adjectives (male vs. female), as in male secretary vs. female secretary, or male elephant vs. female elephant.

iv) Pronouns (he vs. she), as in he rabbit vs. she rabbit, he-devil vs. she-devil, or he-baby vs. she-baby. This resource with persons (for instance, he-doctor vs. she-doctor) is 
cited today as ironic or derogatory.

The model of compounds where the gender marking stem follows the base usually limits itself to using common nouns which generally are lexical pairs of the same kind as those mentioned for pre-position. Thus, $\operatorname{man}^{9}$ or no specification in opposition woman is the most common resource, for instance in fisherman vs. fisherwoman or Englishman vs. Englishwoman. Other options are Man vs. maid (barman vs. barmaid), buck vs. doe (roebuck vs. roe-doe) or cock vs. hen (peacock vs. peahen).

By contrast, the second of the resources mentioned above for the encoding of gender, i.e. lexical resources, make the masculine or the feminine term explicit by use of lexical pairs whose members do not have a derivational relationship, and which make reference to one or the other gender unaided by morphological marks. These lexical pairs are often grouped under three major semantic sets:

i) Kinship relations. For example, in brother vs. sister, nephew vs. niece, widower vs. widow, or bridegroom vs. bride ${ }^{10}$. Some of these masculine/feminine lexical pairs have a third term with dual or common gender reference. This is the case of person (man vs. woman), parent (father vs. mother, and $d a d(d y)$ vs. mum(my)), baby or child (boy vs. girl, and son vs. daughter), spouse (husband vs. wife) and sibling (brother vs. sister).

ii) Terms of social roles or social status. For example, in guy vs. gal (American English), or lad vs. lass (British English, Scottish variety), gentleman or lord vs. lady, king vs. queen, monk vs. nun, or wizard vs. witch.

iii) Names of animals. Here, as in the lexical pairs expressing kinship relations, some pairs have a third term with dual or common gender reference: swine, pig or hog (boar vs. sow), sheep (ram vs. ewe), deer (stag vs. hind), or horse (stallion vs. mare).

\section{Conclusions}

In sum, this diachronic and synchronic review of gender in English has been designed to show the change of its gender system from OE to ModE, and the resources operative in contemporary English to show gender distinction. However, as in many other areas of linguistic description, and despite the growing attention given to gender in the literature, some questions still remain open here, both in the field of diachronic and synchronic linguistics.

In the former, thus, the influence of a number of variables, such as analogy, phonetic changes, or borrowings from other languages, is still to be assessed in relation to the general process of loss of inflections and, as a result, to the mutation from grammatical to natural gender. Or, in the field of synchronic description, overlap of inflectional and derivational morphs in respect of the realization of the morpheme gender by suffixes of the type of '-ess' also wants an agreed reading. 


\section{Notes}

1. I must express my gratitude Dr. Salvador Valera, University of Jaén, for his substantial help in the writing of this paper, as well the two anonymous reviewers who helped in improving this paper by providing relevant feedback on its form and content.

2. This assumption gathered from the BNC, where 'man' features 58,860 occurrences while 'woman' has 22,007 occurrences.

3. By 'grammatical category' we understand the system of forms that represent some feature or property of reality within the structure of a language, in this case, the contrast between male, female, or non-sexed. These properties and this contrast are nearly universal and, accordingly, nearly universally encoded in languages or, at least, in the Indo-European languages (Baugh \& Cable, 1993 : 55-56).

4. However, some verbs have been reported to imply sex (and, hence, gender) discrimination by virtue of what in generative-transformational grammar is known as selectional restrictions. Thus in Frawley's (1992: 100) examples:

The woman gave birth.

-The man gave birth.

5. Loss of inflections thus ran parallel to the development of a fixed word-order which assumed the role of signalling the syntactic function of words (cf. Barber, 1993: 118; Baugh \& Cable, $1993^{4}$ : 162; Hellinger, 2001: 106-110).

6 . The forms for the first and the second persons were invariably indifferent to sex distinctions, because, as pointed out by Jespersen (1909-49, vol. VII: 203), “[...] the sex will practically always appear from the situation [...]".

7. In traditional grammars, common gender is sometimes also called "epicene". The definition of epicene in the OED provides a clear description of what is meant by this: "In Lat. and Gr. grammar, said of nouns which, without changing their grammatical gender, may denote either sex. Hence (improperly) epicene gender. In Eng. grammar the term has no proper application, but is loosely used as a synonym of common" (italics as in the original).

8. 'Productive' is employed here meaning 'available', that is, whether a word-formation process can or cannot be used at a given moment for coining a new word. For the distinction available vs. profitable, see Bauer (2001: 209-210).

9. Man in this use has occasionally been interpreted as having reached the status of a suffix, on account of its productivity and its reduced pronunciation in $/ \mathrm{men} / \mathrm{instead}$ of its full stressed form /mæn/ (Quirk et al., 1985: 1574).

10. The pairs widower vs. widow, and bridegroom vs. bride are sometimes (for example, in Quirk et al., 1985: 315) interpreted as cases of morphological marking of gender by suffixation, as in prince vs. princess, although, as noted above, the productivity of '-er' and '-groom' as gender marking suffixes is very low.

\section{References}

Bammesberger, Alfred (1992): “The place of English in Germanic and Indo-European”. In R.M. Hogg, ed., . The Cambridge History of the English Language. Volume I (The Beginnings to 1066). Cambridge: Cambridge University Press, 26-66. 
Barber, Charles (1993): The English Language: a Historical Introduction. Cambridge: Cambridge University Press.

Baue, Laurie (2001): Morphological Productivity. Cambridge: Cambridge University Press.

Baugh, Albert C. and Thomas Cable $\left(1993^{4}\right)$ : A History of the English Language. London: Routledge \& Kegan Paul.

Blake, Norman F. (1996): A History of the English Language. London: Macmillan.

Brown, Keith and Jim E. Miller (1991²): Syntax. A Linguistic Introduction to Sentence Structure. London: Hutchinson.

Brugmann, Karl (1897): The Nature and Origin of the Noun Genders in the Indo-European Languages. Lecture delivered on the occasion of the sesquicentennial celebration of Princeton University. (Translation by E.Y. Robins). New York: Scirbner's.

Burrow, J.A. and Thorlac Turville-Petre (1992): A Book of Middle English. Oxford: B. Blackwell.

The Compact Edition of the Oxford English Dictionary $\left(1989^{2}\right)$ (Edition prepared by John A. Simpson \& Edmund S.C. Weiner). Oxford: Oxford University Press.

Corbett, Greville G. (1991): Gender. Cambridge: Cambridge University Press.

Fernández, Francisco (1982): Historia de la lengua inglesa. Madrid: Gredos.

Frawley, William (1992): Linguistic Semantics. Hillsdale, N.J.: L. Erlbaum.

Freeborn, Dennis $\left(1998^{2}\right)$ : From Old English to Standard English. London: Macmillan.

Görlach, Manfred (1991): Introduction to Early Modern English. Cambridge: Cambridge University Press.

Gramley, Stephan and Kurt-Michael Pätzold (1992): A Survey of Modern English. London: Routledge.

Guzmán, Trinidad (2001): "On the grammatical category of gender in Old and Middle English again: of linguists, texts and starships". Grove: Working Papers on English Studies 8, 95-110.

Hellinger, Marlis (2001): "English - Gender in a global language". In M. Hellinger and H. Buâmann, eds., Gender across Languages. Amsterdam: J. Benjamins, 105-112.

Hidalgo, Encarnación (2000): "Gender, sex and stereotyping in the Collins COBUILD English Language Dictionary”. Australian Journal of Linguistics 20(2):211-230.

Hogg, Richard M. (1992): "Phonology and morphology". In R.M. Hogg, ed., The Cambridge History of the English Language. Volume I (The Beginnings to 1066). Cambridge: Cambridge University Press, 67-167.

Huddleston, Rodney D (1984): Introduction to the Grammar of English. Cambridge: Cambridge University Press.

Ibrahim, Muhammad Hassan (1973): Grammatical Gender. The Hague: Mouton.

Jespersen, Otto (1909-49): A Modern English Grammar on Historical Principles. London: Allen \& Unwin.

Joseph, Brian D. (2005): "Morphologization from syntax". In R.D. Janda and B.D. Joseph, eds., The Handbook of Historical Linguistics. Oxford: B. Blackwell, 472-492.

Kastovsky, Dieter (1992): "Semantics and vocabulary". In R.M. Hogg, ed., The Cambridge History of the English Language. Volume I (The Beginnings to 1066). Cambridge: Cambridge University Press, 290-408.

Lass, Roger (1992): "Phonology and morphology". In N.F. Blake, ed., The Cambridge History of the English Language. Volume II (1066-1476). Cambridge: Cambridge University Press, 23-155.

Lass, Roger (2006): "Phonology and morphology". In R.M. Hogg and D. Denison, eds., $A$ 
History of the English Language. Cambridge: Cambridge University Press, 43-108.

Mathiot, Madeleine (1979): "Sex roles as revealed through referential gender in American English”. In M. Mathiot, ed., Ethnolinguistics: Boas, Sapir and Whorf Revisited. The Hague: Mouton, 1-47.

Mitchell, Bruce and Fred C. Robinson $\left(2007^{7}\right)$ : A Guide to Old English. Oxford: B. Blackwell.

Moore, Samuel (1968): Historical Outlines of English Sounds and Inflections. (Edition by A.H. Marckwardt). Ann Arbor, Michigan: G. Wahr.

Mossé, Fernand (1952): A Handbook of Middle English. Baltimore: The Johns Hopkins University Press.

Platzer, Hans (2001): “'No sex, please, we're Anglo-Saxon?’ On grammatical gender in Old English". Vienna English Working Papers 10(1): 34-47.

Pyles, Thomas and John Algeo (1993 $)$ : The Origins and Development of the English Language. New York: Harcourt Brace Jovanovich.

Quirk, Randolph, Sidney Greenbaum, Geoffrey Leech and Jan Svartvik (1985): A Comprehensive Grammar of the English Language. London: Longman.

Simpson, John A. and Edmund S.C. Weiner (eds.)(1989): The Oxford English Dictionary. Second edition. Oxford: Clarendon Press.

Traugott, Elizabeth C. (1992): "Syntax". In R.M. Hogg, ed., The Cambridge History of the English Language. Volume I (The Beginnings to 1066). Cambridge: Cambridge University Press, 168-289.

Valera, Salvador (1996): Adjetivos y Adverbios en Inglés: La Relación de Homomorfia. Granada: Universidad de Granada.

Welte, Werner (1989): “Nouns and noun phrases". In R. Dirven and Y. Putseys, eds., A User's Grammar of English: Word, Sentence, Text, Interaction. Part A. Frankfurt am Main: P. Lang, 53-107.

Zubin, David and Klaus-Michael Köpcke (1986): "Gender and folk taxonomy: the identical relation between grammatical and lexical categorization". In C. Craig, ed., Noun Classes and Categorization. Amsterdam: J. Benjamins, 139-180. 